\title{
Towards one Africa, one health: The Southern African Centre for Infectious Disease Surveillance One Health focus on infectious diseases
}

\author{
Authors: \\ Mark M. Rweyemamu ${ }^{1}$ \\ Janusz Paweska ${ }^{1}$ \\ Dominic Kambarage \\ Filomena Namuba

\section{Affiliations:} \\ ${ }^{1}$ Southern African Centre \\ for infectious diseases \\ surveillance, Sokoine \\ University of Agriculture, \\ Tanzania \\ Correspondence to: \\ Mark Rweyemamu \\ Email: \\ mark.rweyemamu@sacids. \\ org \\ Postal address: \\ PO Box 3297, Chuo Kikuu \\ Morogoro, Tanzania \\ How to cite this preface: \\ Rweyemamu, M.M. \\ Paweska, J., Kambarage, \\ D. \& Namuba, F., 2012, \\ 'Towards one Africa, one \\ health: The Southern African \\ Centre for Infectious Disease \\ Surveillance One Health \\ focus on infectious diseases', \\ Onderstepoort Journal of \\ Veterinary Research 79(2), \\ Art. \#449, 2 pages. http:// \\ dx.doi.org/10.4102/ojvr. \\ v79i2.449 \\ Note: \\ Proceedings of the \\ Conference of the Southern \\ African Centre for Infectious \\ Disease Surveillance 'One \\ Health' held at the National \\ Institute for Communicable \\ Diseases, Johannesburg, July \\ 2011.
}

(C) 2012. The Authors. Licensee: AOSIS OpenJournals. This work is licensed under the Creative Commons Attribution License.
The genesis of the Southern African Centre for Infectious Disease Surveillance (SACIDS) is rooted in the realisation that infectious diseases are and will continue to be a formidable challenge to human welfare and economic development in Africa over the horizon of 30 years from 2005, and thereby impede Africa's ability to meet the targets of the UN Millennium Development Goals (MDG). Several recent studies indicate that Africa probably has the highest burden of infectious diseases of humans and animals and yet the least capacity for their detection, identification, monitoring and risk management. Whilst climate change, changing in habitation and farming systems, globalisation of travel and trade are shared drivers for infectious diseases globally, certain other drivers have special relevance to Africa. These include the high human-livestockwildlife interaction, land use and socio-economic settings.

The realisation of opportunities offered by new technologies for risk management of the conventional and emerging communicable diseases in humans and animals will require the integration of research across sectors (human, animal, environment) and disciplines (natural and social science) plus surveillance and disease control strategies that take account of cultural and governance settings. Such approaches will, increasingly, have to be based on ecological systems, which often transcend administrative or national boundaries.

It is against this background that African experts in infectious diseases of humans, animals and plants advocated in 2005 a Pan-African Vision for Infectious Disease Management as:

A Pan-African concerted effort, shared by AU member governments, reflecting the needs of African society and supported by the international community, with the goal of a society protected from the ravages of dangerous infectious diseases that compromise either human health or livelihoods and agriculture and economic development.

They also recommended that such a vision was best developed through national and regional clusters.

The above considerations propelled academic and research institutions involved with infectious diseases of humans and animals (domesticated or wild, terrestrial or aquatic) in southern Africa to form the SACIDS (http:/ / www.sacids.org), with the vision of:

A Southern African society protected from devastating infectious diseases affecting the health of humans, animals, i.e. both terrestrial and aquatic, and plants, i.e. crop, forest and ornamental, thereby promoting livelihoods, socio-economic development including market access and the environment.

The SACIDS Mission is: to harness innovation in science and technology in order to improve southern Africa's capacity (including human, financial and physical) to detect, identify and monitor infectious diseases of humans, animals, plants and their interactions in order to better manage the risk posed by them.

From the standpoint of such a Vision and Mission, the SACIDS 'One Health' focus is to address infectious diseases in the endemic settings of sub-Saharan Africa, with a particular attention to southern, central and East Africa through a collaborative effort between natural and social sciences to advance the understanding of interactions between humans, animals and the environment to improve public and animal health.

Thus the SACIDS model is one of a Virtual Centre that links the core institutions in southern Africa with centres of Excellence in the 'North', bound by a common mission and focus on One Health and whose operation seeks to focus on intra-African as well as South-South-North collaboration.

Our research strategy is reflected in the themes of this conference, namely:

1. Climate dependent, vector-borne diseases.

2. Diseases with potential inter-species concern or spread between wildlife, livestock and humans. 
3. Diseases of economic importance.

4. Bacterial rare diseases.

5. Dangerous emerging diseases.

6. Systems for disease surveillance and preparedness analysis.

7. Socio-economic approaches to One Health policy research.

The SACIDS philosophy is to work towards: One Africa, One Health. Accordingly, we seek to collaborate with other programmes, such as Afrique One, EAIDSNet, (East African Integrated Disease Surveillance Network) OHCEA (One Health Central and Eastern Africa), AFENET (African Field Epidemiology Network), RUFORUM (The Regional Universities Forum for Capacity Building in Agriculture) and others that share this philosophy through a One Health approach, irrespective of their specific strand of emphasis on 'One Health'. The new Strategic Framework of SACIDS to 2020 is:

A Sub-Saharan African society protected from devastating infectious diseases affecting the health of humans, animals, i.e. both terrestrial and aquatic, and ecosystems, thereby promoting livelihoods, socio-economic development including market access and the environment Our convening of the First One Health conference in Africa at the National Institute for Communicable Diseases, Johannesburg is testimony to our commitment to this goal. Over the coming months and years we intend to collaborate with others of like mind to focus our attention on this Vision through the study and application of One Health approaches.

We trust that the readers of this special issue of the Onderstepoort Journal of Veterinary Research will appreciate the diversity of disciplines and expertise that is already beginning to collaborate effectively towards the goal of: One Africa, One Health through smart partnerships.

\section{Acknowledgements}

Southern African Centre for Infectious Disease Surveillance is funded primarily by grants from the Wellcome Trust, Rockefeller Foundation and Google Foundation. We are also grateful to the support of Sokoine University of Agriculture, and those sponsors, such as FAO (Food and Agriculture Organisation) of the United Nations, who have funded some targeted activities. 